\title{
Effects of Mining Activities on Gerbillus nanus in Saudi Arabia; A Biochemical and Histological Study
}

\author{
Ahmed M. Almalki', Jamaan Ajarem ${ }^{1 *}$, Naif Altoom ${ }^{2}$, Fahed S. Al-Otaibi', Saleh N. Maodaa ${ }^{1}$, \\ Ahmed A. Allam ${ }^{3}$ and Ayman M. Mahmoud ${ }^{3 *}$ \\ 1Zoology Department, College of Science, King Saud University, Saudi Arabia; Ah797979@hotmail.com \\ (A.M.A.); jajarem@ksu.edu.sa (J.A.); Fhd243@hotmail.com (F.S.A-O.); maodaa_28@yahoo.com (S.N.M.). \\ ${ }^{2}$ Department of Biology, King Khalid Military Academy, Saudi Arabia; naifaltoom@hotmail.com (N.A.). \\ ${ }^{3}$ Zoology Department, Faculty of Science, Beni-Suef University, Egypt; allam1081981@yahoo.com (A.A.A.); \\ ayman.mahmoud@science.bsu.edu.eg (A.M.M.). \\ * Correspondence: ayman.mahmoud@science.bsu.edu.eg (A.M.M.) and jajarem@ksu.edu.sa (J.A.).
}

Simple Summary: Mining is the extraction of materials of economic importance from the earth. It is an important source of employment and economic development. However, mining activities can impact the biodiversity, environment and human health, mainly through the emission of large quantities of heavy metals. Our objective was to investigate the impact of gold mining on the Balochistan gerbil, a rodent occurs in natural environments in Saudi Arabia. Our results demonstrated the accumulation of heavy metals in the soil, the plant Arabian boxthorn and different tissue of the gerbils. In addition, the gerbils exhibited liver, kidney and lung injury associated with declined antioxidants. These data could be of public interest and may call the attention to evaluate the impact of gold mining on the environment and nearby communities.

\begin{abstract}
Mining can impact the environment, biodiversity and human health through direct and indirect practices. This study investigated the effects of gold mining on Gerbillus nanus, pointing to organ dysfunction and redox imbalance. Soil samples, Lycium shawii and G. nanus were collected from a site near a mining planet and a control site. Soil and L. shawii samples from the mining site showed a significant increase cadmium $(\mathrm{Cd})$, cupper $(\mathrm{Cu})$, mercury $(\mathrm{Hg})$, arsenic (As), zinc (Zn), lead $(\mathrm{Pb})$ and vanadium (V). Hepatic, renal and pulmonary $\mathrm{Cd}, \mathrm{Pb}, \mathrm{Hg}, \mathrm{Zn}, \mathrm{Cu}, \mathrm{Fe}, \mathrm{As}$ and $\mathrm{V}$ concentrations were increased significantly in G. nanus at the mining site. Markers of liver and kidney function were elevated in serum, and several histological manifestations were demonstrated in liver, kidney and lung of G. nanus at the mining site. Malondialdehyde and nitric oxide were increased, and glutathione and antioxidant enzyme were declined in the liver and kidney of G. nanus. In conclusion, mining practices triggered tissue damage and oxidative stress in G. nanus living close to the mining site. These findings can represent the scientific basis for evaluating the environmental and health impact of mining in the on the nearby communities.
\end{abstract}

Keywords: Heavy metals; Mining; Balochistan gerbil; liver injury; Kidney damage.

\section{Introduction}

Mining refers to the extraction of geological materials, such as minerals, coal, limestone and other materials of economic interest from the earth. The mining activities include both small- and large-scale activities and have a significant contribution to the economic growth and development. However, mining activities can impact the environmental and social systems, living standards, health and traditional practices of the nearby communities [1-3]. Erosion, altered soil profile, contamination of soil and local streams and emissions are among the environmental impacts occur during the construction, operation and maintenance of mines [4,5]. Despite its importance as a source of employment and the progress in occupational health and safety, the mining sector remains a highrisk environment where workers are highly susceptible to occupational injuries [6]. 
The widespread contamination of the environment with heavy metals (HMs) is one of main consequences of mining [7]. Owing to their non-degradative nature, increased HMs concentrations can exert long-term negative impact on the ecosystem and human health [8]. HMs possess a high tendency for bioaccumulation and biomagnification and hence trigger serious health problems $[9,10]$. Accordingly, several reports have investigated the in vitro and in vivo toxic effects of HMs [11,12]. Lead $(\mathrm{Pb})$, cadmium $(\mathrm{Cd})$, arsenic $(\mathrm{As})$, mercury $(\mathrm{Hg})$ zinc $(\mathrm{Zn})$ and cupper $(\mathrm{Cu})$ have been determined in the mining waste. Some of these HMs function as essential micronutrients and play central roles in redox processes, biochemical reactions and electron transport chain, whereas the nonessential HMs have no biological importance and are very toxic to the living organisms [13]. Cd is a potent HM pollutant with high tendency for bioaccumulation in living organisms [14]. Exposure to $\mathrm{Cd}$ is common in mining industry and hence pose a health threat to humans [15]. Pb is a welldocumented HM pollutant with hazardous health effects and its worldwide emission rate is high $[9,14]$. The long-term exposure to $\mathrm{Pb}$ and $\mathrm{Cd}$ is linked to the development of liver and neurological disorders, cancer, osteoporosis [11,16], and cardiovascular disease [17]. In rats chronically exposed to $\mathrm{Pb}$ and $\mathrm{Cd}$, liver and heart tissue injury and oxidative damage have been observed [12]. As is a very dangerous pollutant that attracted significant worldwide attention due to its potential toxic effects [18]. Lung, kidney and skin cancers, cardiovascular and neural alterations, hepatomegaly, peripheral vascular disease and others might be triggered by exposure to As (reviewed by [19]). $\mathrm{Hg}$ is another serious HM that can induce cell death via binding cysteine residues of proteins and depletion of cellular antioxidants [20].

Given the hazardous impact of mining and its HMs waste on the environment, society and health, we investigated the impact of mining on the Balochistan gerbil (Gerbillus nanus) in Riyadh (Saudi Arabia). G. nanus belongs to the murid subfamily Gerbillinae [21] and occurs in natural environments in Saudi Arabia [22], and is therefore selected to be investigated.

\section{Materials and Methods}

\subsection{Study site and collection of samples}

Samples were collected from the area of mining activities in Al-Quway'iyah, a city located 165 $\mathrm{km}$ west to Riyadh Province (Saudi Arabia). This city is one of the large governorates in Saudi Arabia and hence selected for the study.

The investigated gold mine site is located southwestern to Al-Quway'iyah city. The samples were collected from two sites as following (Fig. 1):

Site 1 (Mining): Located at $500 \mathrm{~m}$ from the gold mine between E45 05' and N23 47'.

Site 2 (Control): Located at $20000 \mathrm{~m}$ away from the gold mine between E45 06' and N23 36 '.

Samples from the soil at $20 \mathrm{~cm}$ depth $(\mathrm{N}=8)$ and Lycium shawii (Arabian boxthorn) $(\mathrm{N}=8)$ were collected from both sites for the determination of HMs. Eight G. nanus were collected from each site with the help of specific rodent traps and were transferred to the laboratory. The animals were sacrificed under anesthesia and blood and tissue samples were collected for analysis. The protocol and procedures were approved by the institutional animal ethics committee of King Saud University (No. KSU-20165). 


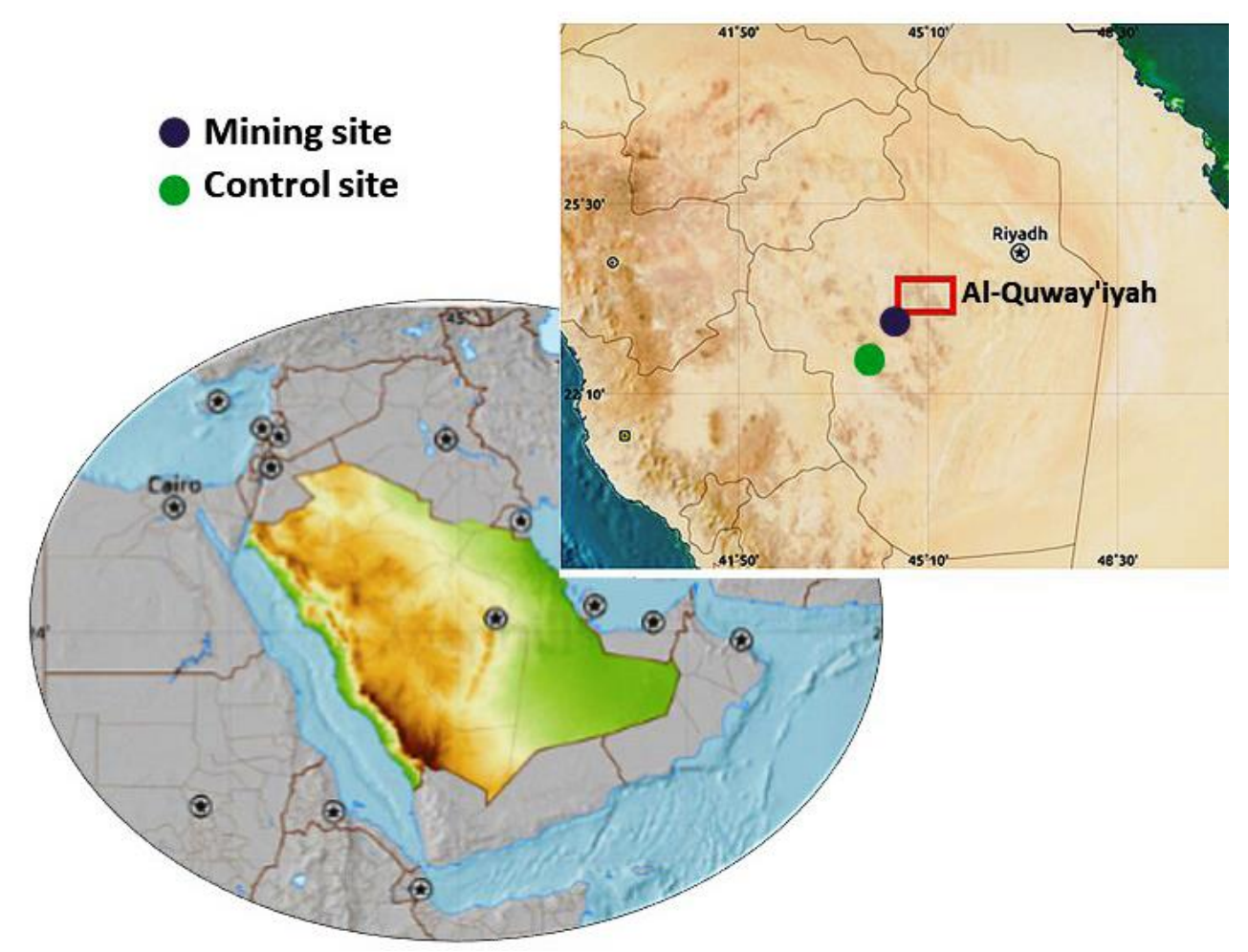

Figure 1. Location map of the mining and control sites.

\subsection{Determination of HMs}

The concentrations of HMs were determined in soil, L. shawii, and G. nanus kidney, liver, and lung using ELAN 9000 ICP/MS (Perkin Elmer Sciex Instruments, Canada).

\subsection{Assay of liver and kidney function markers}

Serum alanine transaminase (ALT), aspartate transaminase (AST), alkaline phosphatase (ALP), creatinine, urea and uric acid were measured using Biomerieux (France) reagent kits, following the manufacturer's instructions.

\subsection{Assay of oxidative stress markers and antioxidants}

Samples from the liver and kidney were homogenized in phosphate buffered saline $(10 \% \mathrm{w} / \mathrm{v})$, centrifuged and the supernatant was used for the assays. Malondialdehyde (MDA) [23], nitric oxide (NO) [24], reduced glutathione (GSH) [25], superoxide dismutase (SOD) [26] and catalase (CAT) [27] were assayed in the liver and kidney homogenate samples. Protein content was determined using Bradford assay.

\subsection{Histological study}

Samples from the kidneys, liver and lungs of G. nanus collected form the mining and control sites were fixed 10\% neutral buffered formalin and processed for paraffin embedding. $5 \mu \mathrm{m}$ sections were cut, stained with hematoxylin and eosin (H\&E) and examined using a light microscope.

\subsection{Statistical analysis}

Data were analyzed using GraphPad Prism 7 (La Jolla, CA, USA) and expressed as means \pm standard error of means (SEM). All statistical comparisons were performed using T. test and a $P$ value $<0.05$ was considered significant.

\section{Results}




\subsection{HMs concentration in soil and L. shawii samples}

The concentration of HMs has been determined in soil samples collected from the control and mining site. $\mathrm{Pb}, \mathrm{V}, \mathrm{Cu}, \mathrm{As}, \mathrm{Zn}, \mathrm{Cd}$ and $\mathrm{Hg}$ were increased significantly $(\mathrm{P}<0.05)$ at the mining site when compared with the control site (Fig. 2A). The results revealed non-significant difference in Fe concentration between both sites. L. shawii samples at the mining site showed higher concentrations of $\mathrm{Pb}, \mathrm{V}, \mathrm{Cu}, \mathrm{As}, \mathrm{Fe}, \mathrm{Cd}$ and $\mathrm{Hg}$, whereas $\mathrm{Zn}$ concentration wasn't significantly different when compared with the control site (Fig. 2B).

\subsection{Concentration of HMs in liver, kidney and lung of G. nanus}

$\mathrm{Pb}, \mathrm{Cd}$ and $\mathrm{Hg}$ levels were increased significantly in the liver, kidney and lung of G. nanus collected from the mining site when compared with the control site animals, as depicted in Figures 3A-3C. Similarly, V (Fig. 3D), Cu (Fig. 3E) and Zn (Fig. 3F) were significantly increased in the target tissues of G. nanus at the mining site. Fe (Fig. 3G) and As (Fig. 3H) were also increased remarkably in the liver, kidney and lung of G. nanus at the mining site.

\subsection{Effect of mining on liver function and histology in G. nanus}

The liver function markers ALT, AST and ALP were elevated in serum of G. nanus at the mining site $(\mathrm{P}<0.05)$ when compared with the corresponding control site animals (Fig. 4A). Examination of the liver section showed normal structure of the hepatic lobules and hepatocytes in G. nauns at the control site (Fig. 4Ba and b). In contrast, G. nanus at the mining site showed hepatocyte vacuolations, hemorrhages and dilated central vein (Fig. 4Bc and d).

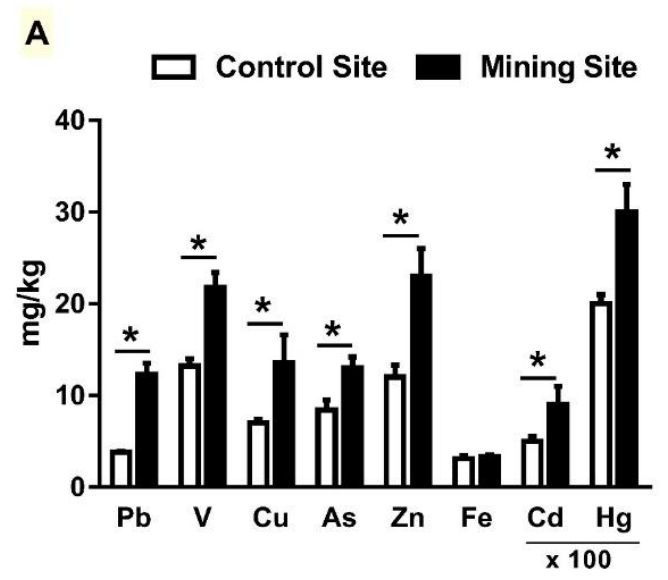

B

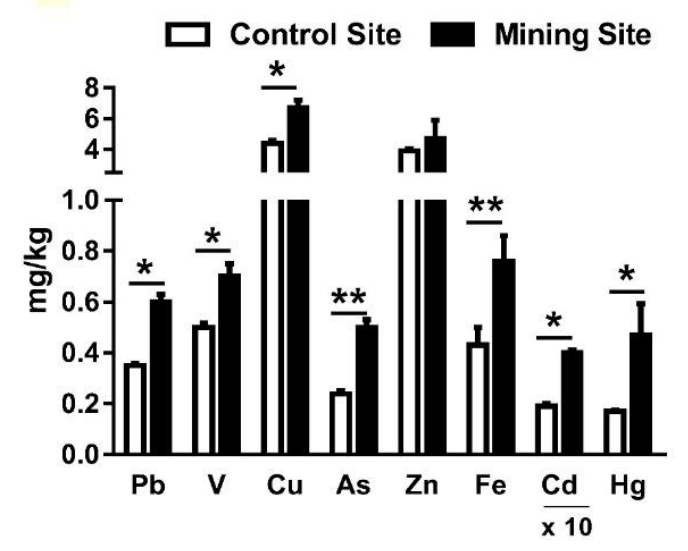

Figure 2. Concentration of heavy metals in (A) soil and (B) L. shawii at the mining and control sites. Data are means $\pm \mathrm{SEM},(\mathrm{N}=8)$. ${ }^{*} \mathrm{P}<0.05$ and ${ }^{* *} \mathrm{P}<0.01$. 


\subsection{Effect of mining on kidney function and histology in G. nanus}

Serum creatinine, urea and uric acid were elevated significantly $(\mathrm{P}<0.05 ; \mathrm{P}<0.01 ; \mathrm{P}<0.05)$ in $G$. nanus at the mining site (Fig. 5A). While the control site G. nanus showed normal kidney (Fig. 5Ba and b), animals at the mining site exhibited glomerular degeneration (Fig. 5Bc and d).

A

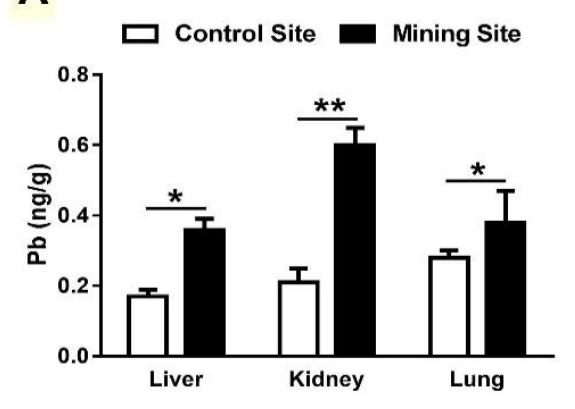

C

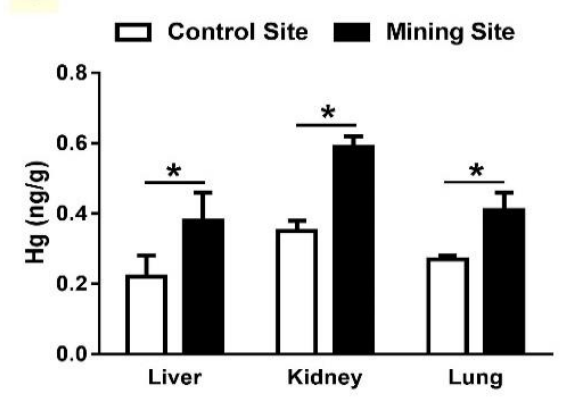

E

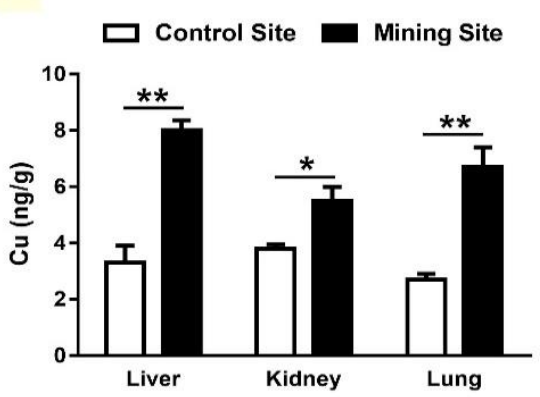

G

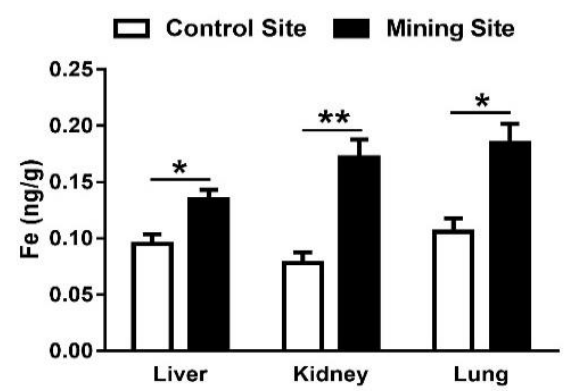

B

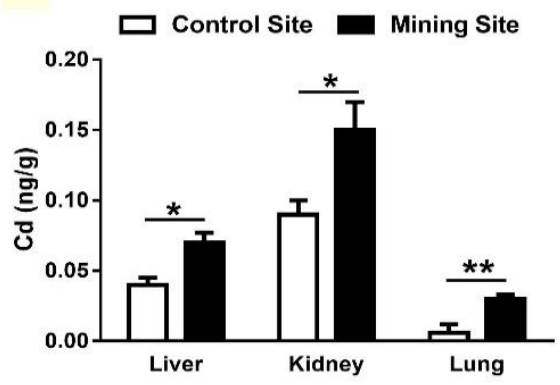

D

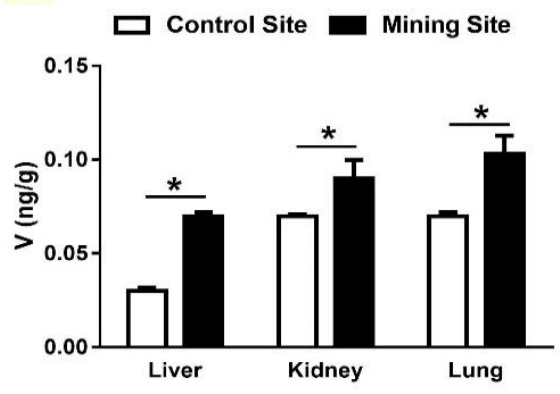

$\mathbf{F}$

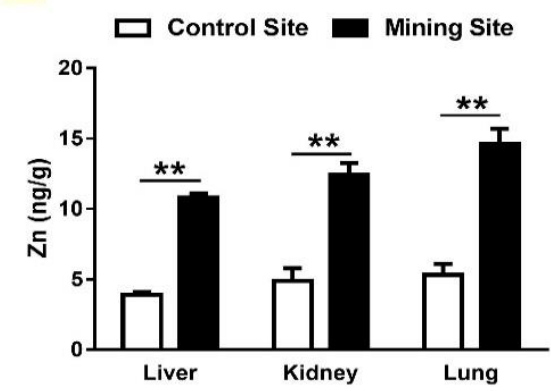

H

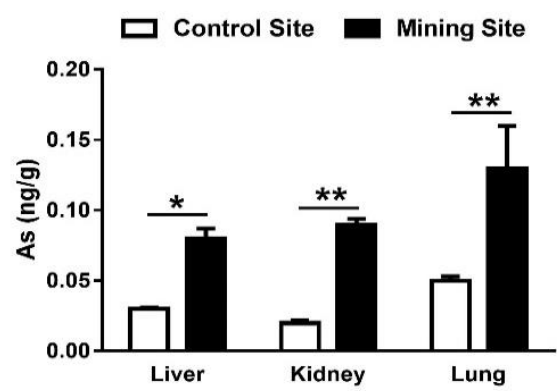

Figure 3. Concentration of heavy metals in liver, kidney and lung of G. nanus at the mining and control sites. Data are means $\pm \mathrm{SEM},(\mathrm{N}=8) .{ }^{*} \mathrm{P}<0.05$ and ${ }^{* *} \mathrm{P}<0.01$. 
A

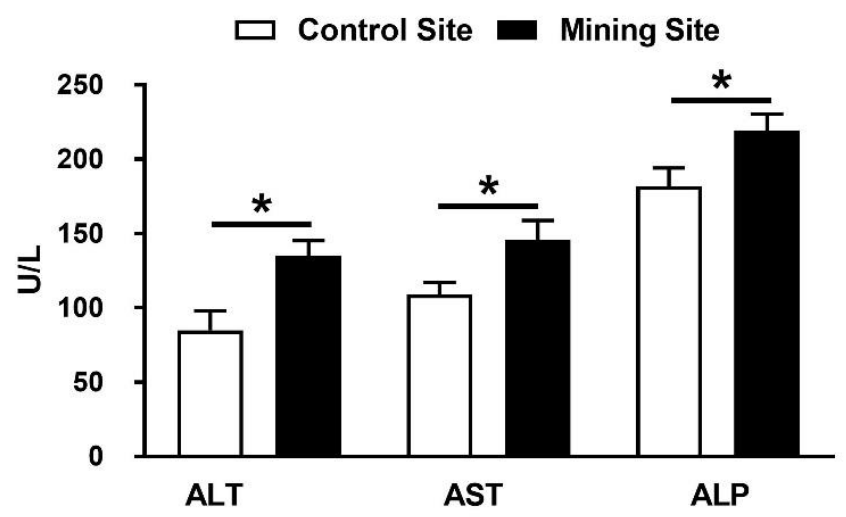

B
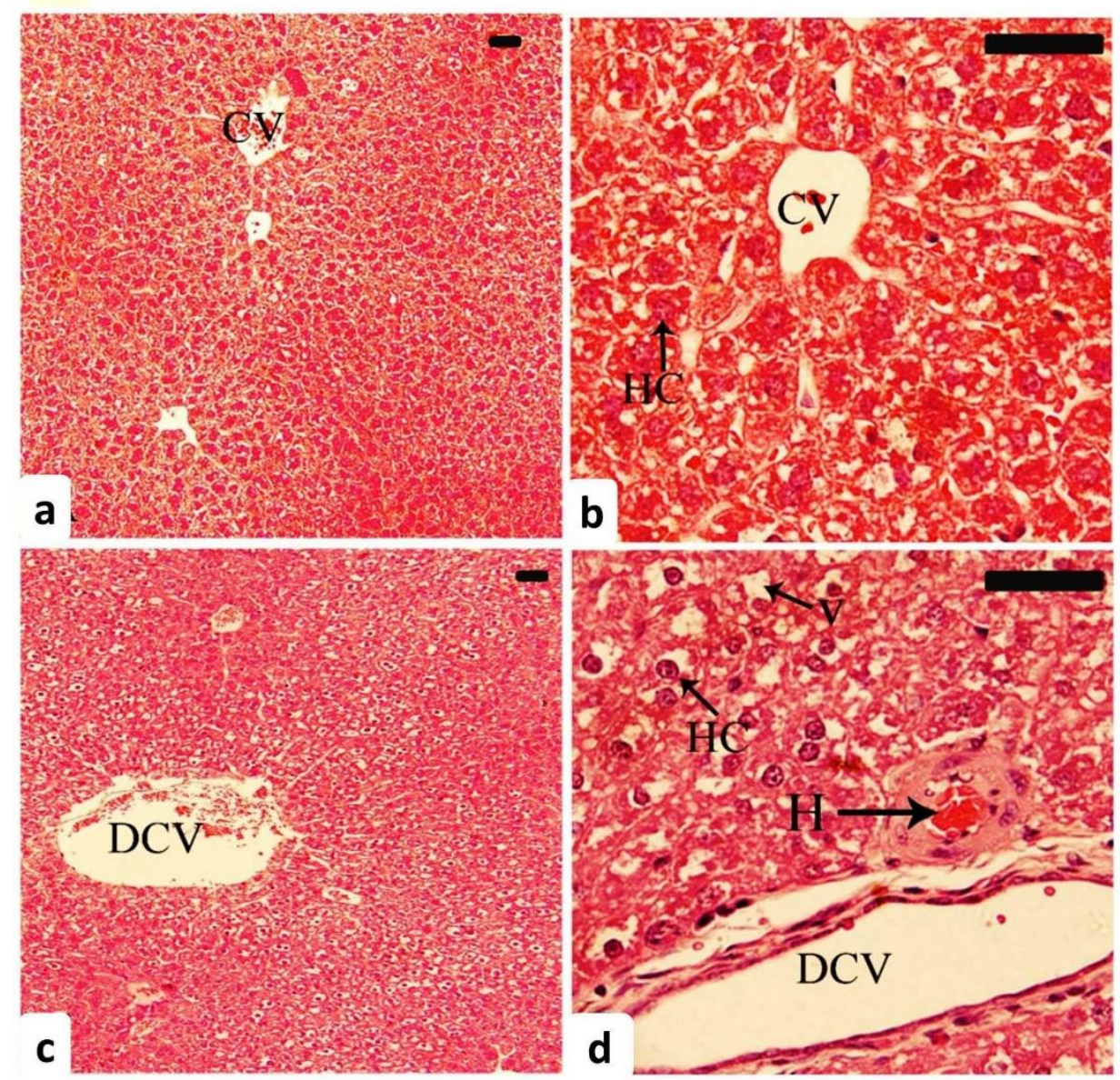

Figure 4. Effect of mining activities on liver function markers (A) of G. nanus. Data are means \pm SEM, $(\mathrm{N}=8) .{ }^{*} \mathrm{P}<0.05$. (B) Photomicrographs of H\&E-stained sections in liver of G. nanus at the control site ( $a$ and b) showing normal structure of hepatocytes $(\mathrm{HC})$ and central vein $(\mathrm{CV})$, and animals at the mining site (c and d) showing dilated central vein (DCV), hemorrhage $(\mathrm{H})$ and vacuolations $(\mathrm{V})$. [Scale bar $=100 \mu \mathrm{m}]$. 
A

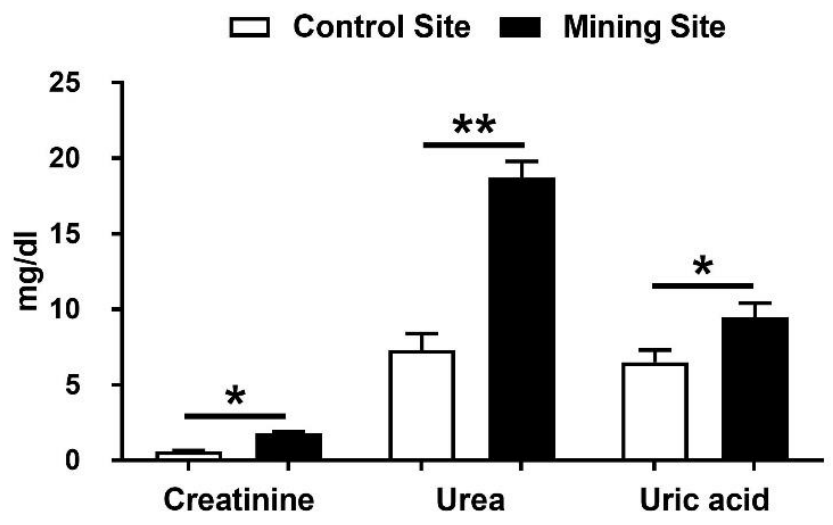

B

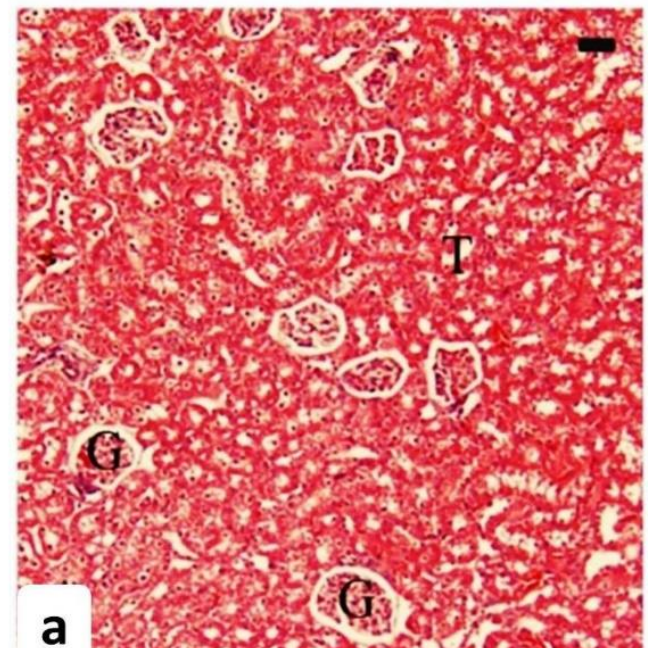

a
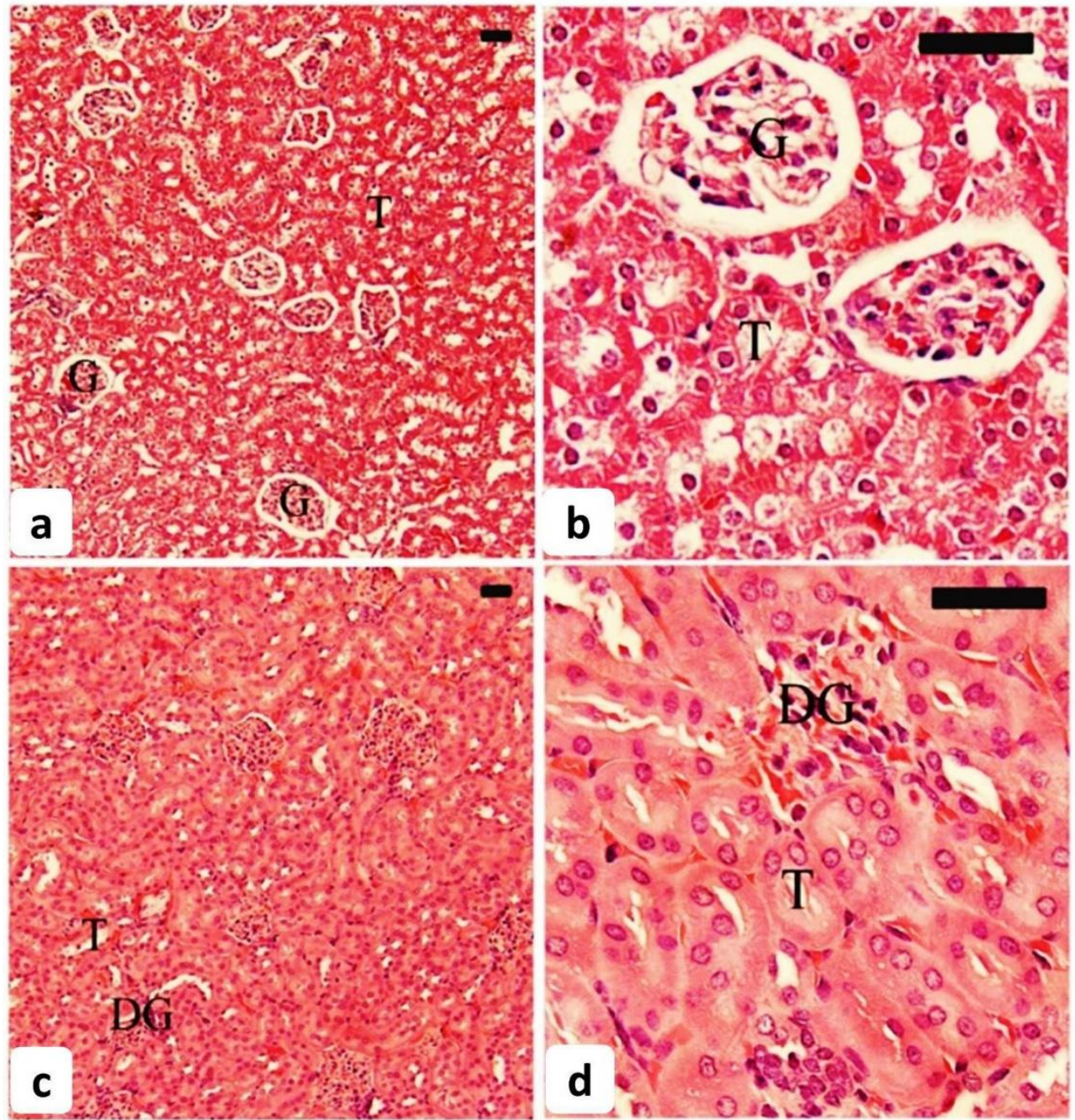

Figure 5. Effect of mining activities on renal function markers (A) of G. nanus. Data are means \pm SEM, $(\mathrm{N}=8) .{ }^{*} \mathrm{P}<0.05$ and ${ }^{*} \mathrm{P}<0.01$. (B) Photomicrographs of H\&E-stained sections in kidney of $G$. nanus at the control site ( $a$ and $b$ ) showing normal structure of the glomeruli $(\mathrm{G})$ and renal tubules $(\mathrm{T})$, and animals at the mining site (c and d) showing degenerated glomeruli (DG). [Scale bar $=100 \mu \mathrm{m}$ ]. 
As represented in Figures 6A and 6B, the lung of G. nanus at the control site showed normal structure of the bronchioles and alveoli. In contrast, the lung of animals at the mining site showed dilated alveoli, inflammatory cells infiltration and congested blood vessels (Fig. 7C and D).

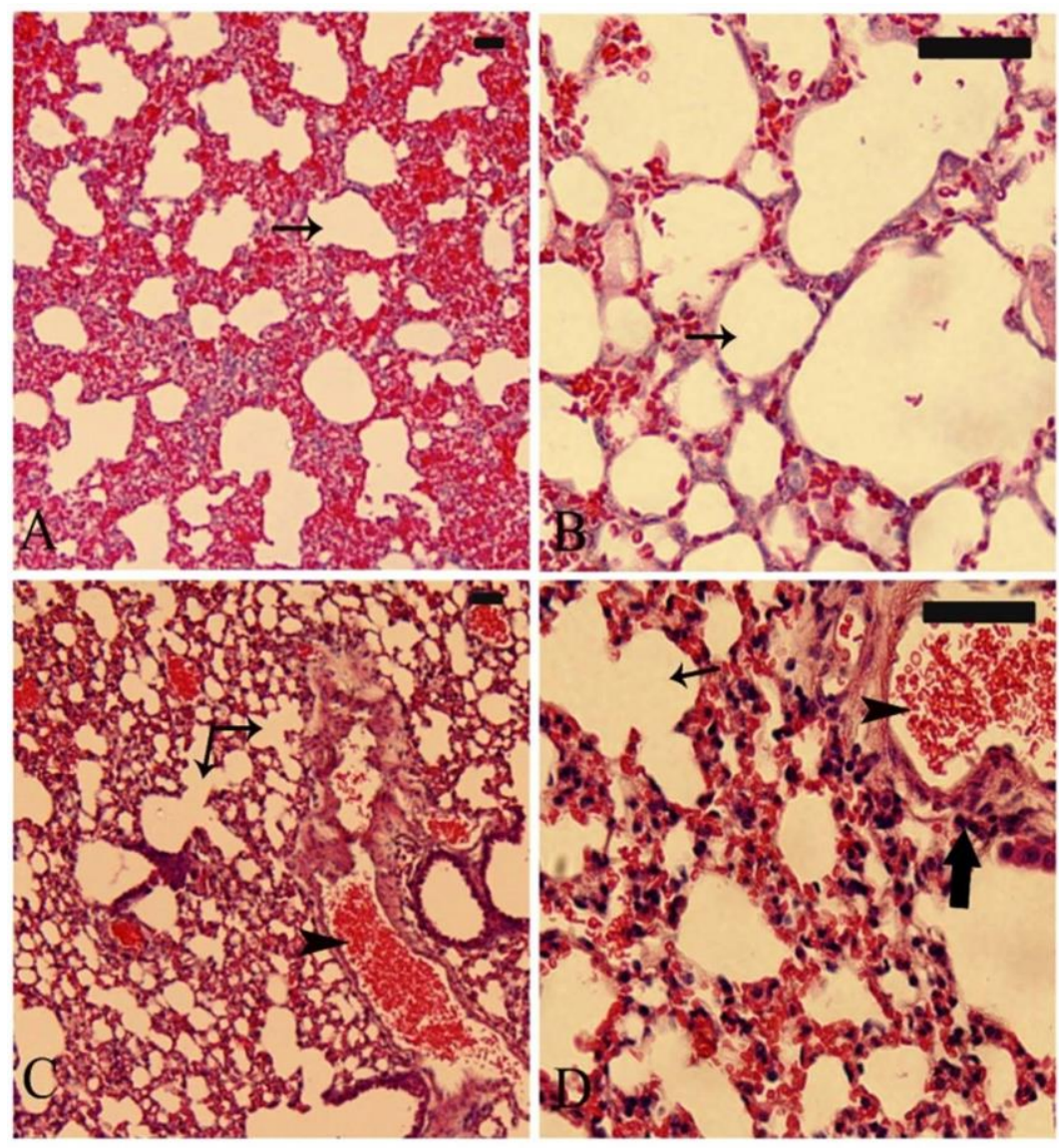

Figure 6. Photomicrographs of H\&E-stained sections in lung of G. nanus at the control site ( $a$ and b) showing normal structure of the bronchioles and alveoli (arrow), and the lung of animals at the mining site showing dilated alveoli (thin arrow), inflammatory cells infiltration (thick arrow) and congested blood vessels (arrow head). [Scale bar $=100 \mu \mathrm{m}$ ].

\subsection{Effect of mining on hepatic and renal redox balance in $G$. nanus}

To evaluate the impact of mining on the redox balance in G. nanus, we determined lipid peroxidation (LPO), NO, and cellular antioxidants in the liver and kidney. G. nanus at the mining site showed remarkable increase in hepatic $(\mathrm{P}<0.001)$ and renal $(\mathrm{P}<0.01)$ LPO (Fig. 7A). Similarly, hepatic and renal $\mathrm{NO}$ was increased significantly $(\mathrm{P}<0.01)$ in $\mathrm{G}$. nanus at the mining site (Fig. $7 \mathrm{~B})$. When compared with the control site, animals at the mining site showed a decrease in hepatic and renal GSH content $(\mathrm{P}<0.01 ; \mathrm{P}<0.01$; Fig. $7 \mathrm{C})$, SOD $(\mathrm{P}<0.01 ; \mathrm{P}<0.01$; Fig. $7 \mathrm{D})$ and CAT $(\mathrm{P}<0.05 ; \mathrm{P}<0.01$; Fig. $7 \mathrm{E}$. 
A

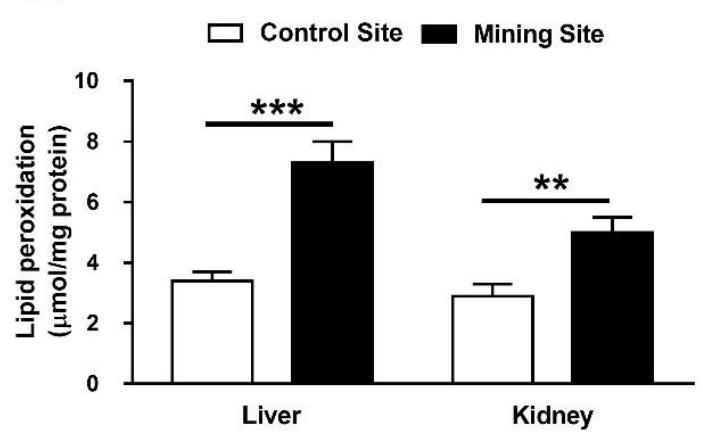

C

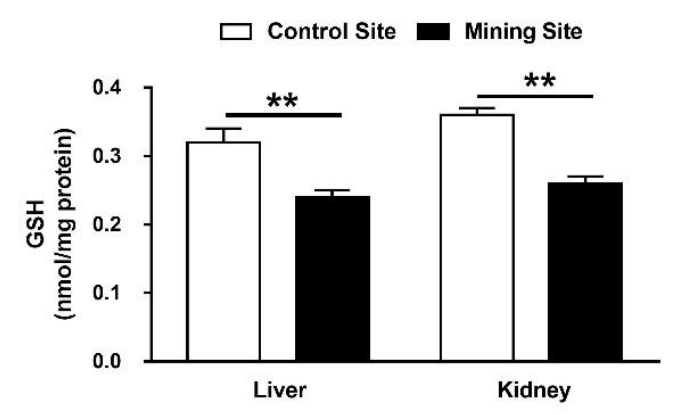

B

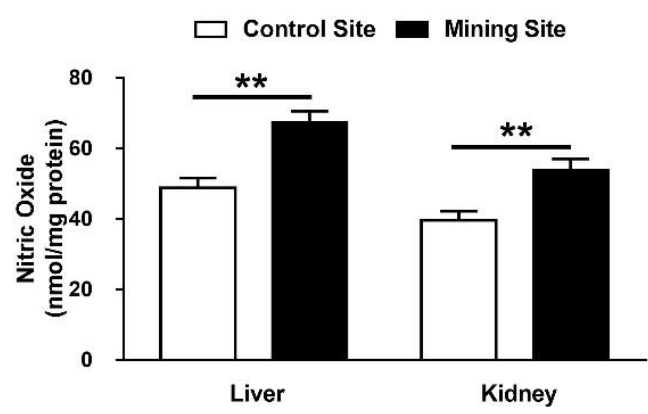

D

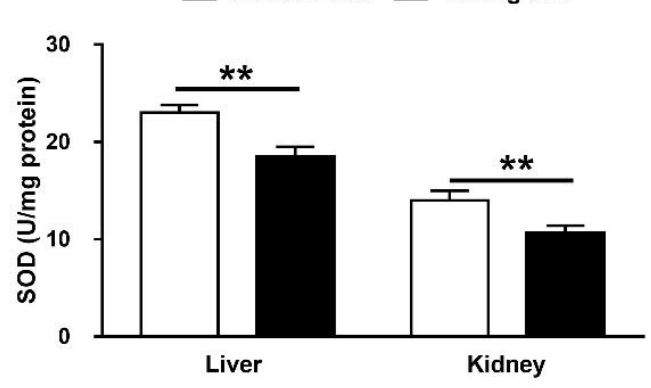

$\mathbf{E}$

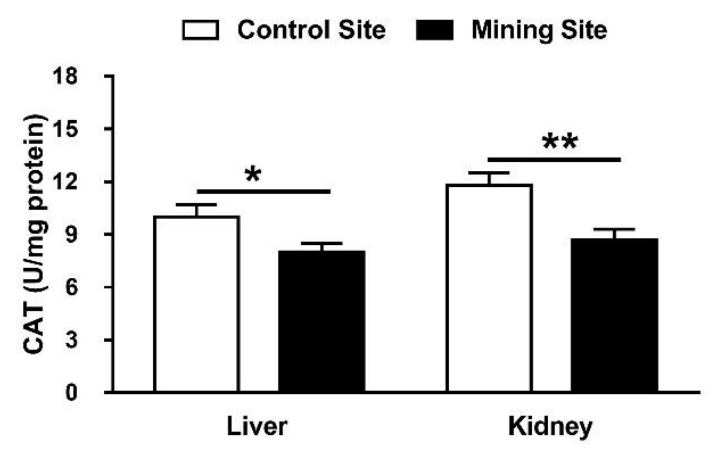

Figure 7. Effect of mining activities on oxidative stress and antioxidants in liver and kidney of $G$. nanus. Animals at the mining site showed an increase in (A) lipid peroxidation and (B) nitric oxide, and decreased (C) GSH, (D) SOD and (E) CAT in liver and kidney. Data are means \pm SEM, (N = 8). ${ }^{*} \mathrm{P}<0.05,{ }^{* *} \mathrm{P}<0.01$ and ${ }^{* * *} \mathrm{P}<0.001$.

\section{Discussion}

This study evaluated the impact of mining activities at Al-Quway'iyah, Riyadh (Saudi Arabia) on G. nanus with an emphasis on HMs accumulation and redox imbalance. To evaluate the emission and distribution of $\mathrm{HMs}$ in the mining site, we determined the concentrations of $\mathrm{Pb}, \mathrm{V}, \mathrm{Cu}, \mathrm{As}, \mathrm{Zn}$, $\mathrm{Cd}, \mathrm{Fe}$ and $\mathrm{Hg}$ in soil and L. shawii samples, and different organs of $\mathrm{G}$. nauns. $\mathrm{Pb}, \mathrm{V}, \mathrm{Cu}, \mathrm{As}, \mathrm{Cd}$ and $\mathrm{Hg}$ were increased in both collected samples of soil and L. shawii. Fe and Zn concentrations were not significantly increased in soil and L. shawii, respectively. These findings showed the effect of mining on the soil profile as well as plants growing in the nearby areas.

Despite their negative impact on the ecosystem and adverse health effects, exposure to HMs continues to increase in many regions [28]. Here, $\mathrm{Pb}, \mathrm{V}, \mathrm{Cu}, \mathrm{As}, \mathrm{Zn}, \mathrm{Cd}, \mathrm{Fe}$ and $\mathrm{Hg}$ were increased in the liver, kidney and lung of G. nanus. Besides their environmental impact, these HMs have been 
proven to be a major threat to the body systems and its proper functioning [28]. In accordance, liver and kidney dysfunction along with histopathological manifestations in the liver, kidney and lung of G. nanus were observed. These hazardous effects were directly connected to the accumulation of HMs in different tissues of $G$. nanus.

$\mathrm{Pb}, \mathrm{Cd}$, As and $\mathrm{Hg}$ have been demonstrated as the common $\mathrm{HM}$ pollutants produced through various human activities, including mining, and all of which are hazardous to the human health. $\mathrm{Pb}$ is a highly toxic HM whose widespread use resulted in health problems as well as environmental contamination. It has been estimated that 540000 deaths per year, particularly in developing countries occur due to $\mathrm{Pb}$ contamination [29] and that 26 million people are at the risk [30]. The most common depository of $\mathrm{Pb}$ within the body are the liver and kidneys [31], and this might explain the observed hepato- and nephrotoxicity in G. nanus at the mining site. The accumulation of $\mathrm{Pb}$ in liver and kidney, elevated transaminases, ALP, and renal function markers along with the histopathological changes indicated the injury of liver and kidney tissues. In this context, in vivo studies have demonstrated both hepato- and nephrotoxicity in rodents exposed to low concentrations of $\mathrm{Pb}$ [32-34]. The toxicity of $\mathrm{Pb}$ has been attributed mainly to its ionic properties and induction of redox imbalance [35]. It can disturb cellular signaling and metabolism, ionic transportation and enzyme activities through replacing mono- and bivalent cations [36]. In addition to its ionic activity, Pb triggers the generation of reactive oxygen species (ROS) which promote oxidative damage to lipids, DNA and proteins [37]. In accordance, LPO and NO were elevated accompanied with depletion of the cellular antioxidants in $\mathrm{G}$. nanus at the mining site, demonstrating an oxidative stress status. Furthermore, $\mathrm{Pb}$ concentration was increased in the lung of G. nanus which showed dilation of alveoli, infiltration of inflammatory cells and congestions. The relationship between lung injury and $\mathrm{Pb}$ accumulation was supported by the findings of $\mathrm{Li}$ et al who demonstrated increased $\mathrm{Pb}$ concentration in the lungs of rats following exposure to atmospheric fine particulate matter [38].

$\mathrm{Cd}$ is a is a highly toxic nonessential HM and serious environmental pollutant. When released to the environment, $\mathrm{Cd}$ can remain for several decades in soils and sediments because of the lack of degradability $[39,40]$. It has a high rate of soil-to-plant transfer and is therefore accumulates in plants, predominantly in vegetables and fruits, and ultimately reach the human body [41]. The present study showed accumulation of $\mathrm{Cd}$ in the soil and L. shawii samples collected from the mining site. In addition, $\mathrm{Cd}$ concentrations were increased in different tissues of $\mathrm{G}$. nanus and its accumulation was associated with oxidative stress, hepato-/nephrotoxicity and lung injury. Although the exact mechanisms of $\mathrm{Cd}$ toxicity are not fully elucidated, the role of oxidative stress has been wellacknowledged. Cd produces hydrogen peroxide which acts as a source of free radicals generated via Fenton reaction [42], and its toxicity has been reported to cause injury of liver and kidney $[43,44]$. Upon exposure, $\mathrm{Cd}$ binds to albumin and is taken up and deposits primarily in the liver [45]. Within the liver, Cd promotes ROS generation, LPO and membrane damage, GSH depletion and cell death [46]. Cd binds to metallothionine and the produced complexes induce liver injury and circulate to the kidney where they accumulate and cause renal tissue injury [47]. The activity of SOD and CAT was declined in the liver and kidney of G. nanus at the mining site and this results from the binding of $\mathrm{Cd}$ with the thiol groups of these enzymes [48]. In addition, $\mathrm{Cd}$ can inhibit complex III of the mitochondrial electron transport chain [48]. The observed nephrotoxicity in this study was associated with glomerular degeneration which has been shown in rats exposed to Cd [49]. Furthermore, the lungs represent one of the main routes through which Cd enters the body [40]. G. nanus in this study showed lung injury associated with elevated $\mathrm{Cd}$ concentration. The potential of $\mathrm{Cd}$ to provoke pulmonary toxicity has been supported by studies reported bronchial and pulmonary irritation, transient bronchial inflammation [50], diminished pulmonary function [51], and primary lung cancers [52] following exposure to $\mathrm{Cd}$.

Mining is one of the major sources of As and $\mathrm{Hg}$ pollution. Accordingly, As and $\mathrm{Hg}$ were found in high concentrations in the soil, L. shawii and different tissue of G. nanus collected from the mining site. As is extensively available in different forms and possesses toxic and carcinogenic effects [53]. The toxicity of As includes the formation of inorganic arsenic species (iAs) monomethylarsonic acid and dimethylarsinic acid which produce methylated arsenicals via enzymatic conversion. Monomethylarsonic acid, an intermediate product produced during the transformation of iAs, is 
highly toxic and carcinogenic [53]. The toxicity of As has been associated with its ability to increase ROS levels, activate apoptosis signaling, alter metabolism and energy generation, and replace metal ions in cellular biomolecules [54]. Therefore, the accumulation of As in G. nanus has a role in the observed oxidative stress, and hepato-/nephrotoxicity. Accordingly, recent reports have shown Asinduced hepatic, renal and pulmonary manifestations in experimental animals [55-57].

$\mathrm{Hg}$ is a well-known HM pollutant and its toxicity is commonly responsible for acute HM poisoning. Although neurotoxicity is the most common effect of $\mathrm{Hg}$ and methylmercury which induced LPO and cell death [58], it can cause nephrotoxicity [59] and hepatotoxicity [60]. Hence, $\mathrm{Hg}$ accumulation in $G$. nanus participated, at least in part, to liver and kidney injury and redox imbalance.

$\mathrm{V}, \mathrm{Cu}, \mathrm{Zn}$ and Fe were the other HMs shown to accumulate in the soil, L. shawii, and different tissues of G. nanus at the mining site. $\mathrm{V}$ is considered as an environmental pollutant that possess hazardous effects, and inhalation of vanadium pentoxide dust has caused occupational toxicity [61]. Liver injury and other toxic effects have been demonstrated in rats exposed to V [62], and inhalation of $\mathrm{V}$ caused bronchopneumonia and chronic productive cough [63,64]. Cu exists in oxidized [Cu(II)] and reduced $[\mathrm{Cu}(\mathrm{I})]$ states and is therefore considered as potentially toxic. Generation of ROS during the conversion between the oxidized and reduced states represent the main reason of $\mathrm{Cu}$ toxicity [65]. $\mathrm{Zn}$ is an essential micronutrient needed for vital cell functions in microorganisms, plants and human; however, concentrations beyond the physiological value are toxic. At high concentrations, $\mathrm{Zn}$ interacts with sulfhydryl groups or replaces other essential metals in different cellular proteins [66]. Iron is a vital nutrient that acts as cofactor for multiple enzymes within the living cells. It mediates reactions that can catalyze the formation of free radicals, leading to cell damage. Hence, iron overload can induce toxicity particularly in children [67], hepatotoxicity [68] and nephrotoxicity [69]. Therefore, excess V, $\mathrm{Cu}$. $\mathrm{Zn}$ and Fe are associated with ROS generation and participate in liver, kidney and lung injury in G. nanus living close to the mining site.

\section{Conclusions}

These findings highlight the hazardous effects of mining activities on the soil, plants and animals. HMs were increased in the soil and L. shawii at the mining site, demonstrating the negative environmental impact of mining. G. nanus living at the mining site exhibited hepato- and nephrotoxicity, and lung manifestations. The deleterious effects of mining activities on G. nanus were associated with oxidative stress and depletion of antioxidants. These results demonstrated the environmental and health impact of mining and might represent the scientific basis for evaluating the effects of mining on the nearby communities.

Author Contributions: Cconceptualization, A.M.M.; J.A. and A.A.A.; methodology, A.M.A.; A.M.M.; J.A.; A.A.A. and S.N.M.; validation, J.A.; A.A.A. and A.M.M.; formal analysis, A.M.M.; investigation, A.M.A.; A.M.M.; J.A.; A.A.A.; S.N.M.; F.S.A-O and N.A.; resources, F.S.A-O and N.A.; data curation, A.M.A. and A.M.M..; writing - original draft preparation, A.M.M.; writing - review and editing, A.M.M.; visualization, J.A.; A.A.A.; A.M.A.; supervision, A.M.M.; J.A. and A.A.A.; project administration, J.A. and A.A.A.; funding acquisition, J.A."

Funding: This research was funded by the Dean of Scientific Research, King Saud University, grant number RGP-VPP-240.

Acknowledgments: We extend our appreciation to the Dean of Scientific Research, King Saud University, for funding the work through the research group project number RGP-VPP-240.

Conflicts of Interest: The authors declare no conflict of interest."

\section{References}

1. Krook, J.; Svensson, N.; Eklund, M. Landfill mining: A critical review of two decades of research. Waste Management 2012, 32, 513-520.

2. Loayza, N.; Rigolini, J. The local impact of mining on poverty and inequality: Evidence from the commodity boom in peru. World Development 2016, 84, 219-234. 
3. Emmanuel, A.Y.; Jerry, C.S.; Dzigbodi, D.A. Review of environmental and health impacts of mining in ghana. Journal of Health and Pollution Journal of Health and Pollution 2018, 8, 43-52.

4. Dudka, S.; Adriano, D.C. Environmental impacts of metal ore mining and processing: A review. Journal of Environmental Quality 1997, 26, 590-602.

5. Warhate, S.R.; Yenkie, M.K.; Chaudhari, M.D.; Pokale, W.K. Impacts of mining activities on water and soil. Journal of environmental science E engineering 2006, 48, 81-90.

6. Nowrouzi-Kia, B.; Gohar, B.; Casole, J.; Chidu, C.; Dumond, J.; McDougall, A.; Nowrouzi-Kia, B. A systematic review of lost-time injuries in the global mining industry. Work (Reading, Mass.) 2018, 60, 49-61.

7. Fashola, M.O.; Ngole-Jeme, V.M.; Babalola, O.O. Heavy metal pollution from gold mines: Environmental effects and bacterial strategies for resistance. Int J Environ Res Public Health 2016, 13, 1047.

8. Singh, R.; Gautam, N.; Mishra, A.; Gupta, R. Heavy metals and living systems: An overview. Indian journal of pharmacology 2011, 43, 246-253.

9. Jarup, L. Hazards of heavy metal contamination. British medical bulletin 2003, 68, 167-182.

10. Rzymski, P.; Niedzielski, P.; Klimaszyk, P.; Poniedzialek, B. Bioaccumulation of selected metals in bivalves (unionidae) and phragmites australis inhabiting a municipal water reservoir. Environmental monitoring and assessment 2014, 186, 3199-3212.

11. de Kok, T.M.; Hogervorst, J.G.; Briede, J.J.; van Herwijnen, M.H.; Maas, L.M.; Moonen, E.J.; Driece, H.A.; Kleinjans, J.C. Genotoxicity and physicochemical characteristics of traffic-related ambient particulate matter. ENVIRONMENTAL AND MOLECULAR MUTAGENESIS 2005, 46, 71-80.

12. Markiewicz-Górka, I.; Januszewska, L.; Michalak, A.; Prokopowicz, A.; Januszewska, E.; Pawlas, N.; Pawlas, K. Effects of chronic exposure to lead, cadmium, and manganese mixtures on oxidative stress in rat liver and heart. Arhiv za higijenu rada i toksikologiju 2015, 66, 51-62.

13. Rzymski, P.; Tomczyk, K.; Rzymski, P.; Poniedzialek, B.; Opala, T.; Wilczak, M. Impact of heavy metals on the female reproductive system. Annals of agricultural and environmental medicine : AAEM 2015, 22, 259-264.

14. Lin, Y.F.; Aarts, M.G. The molecular mechanism of zinc and cadmium stress response in plants. Cellular and molecular life sciences : CMLS 2012, 69, 3187-3206.

15. Nordberg, G.F.; Nogawa, K.; Nordberg, M.; Friberg, L.T. Chapter 23 - cadmium. In Handbook on the toxicology of metals (third edition), Academic Press: Burlington, 2007; pp 445-486.

16. Brzoska, M.M.; Moniuszko-Jakoniuk, J. Low-level exposure to cadmium during the lifetime increases the risk of osteoporosis and fractures of the lumbar spine in the elderly: Studies on a rat model of human environmental exposure. Toxicological sciences : an official journal of the Society of Toxicology 2004, $82,468-477$.

17. Alissa, E.M.; Ferns, G.A. Heavy metal poisoning and cardiovascular disease. Journal of toxicology 2011, $2011,870125$.

18. Choudhury, B.; Chowdhury, S.; Biswas, A.K. Regulation of growth and metabolism in rice (oryza sativa 1.) by arsenic and its possible reversal by phosphate. Journal of Plant Interactions 2011, 6, 15-24.

19. Rahman, Z.; Singh, V.P. The relative impact of toxic heavy metals (thms) (arsenic (as), cadmium (cd), chromium (cr)(vi), mercury (hg), and lead (pb)) on the total environment: An overview. Environmental monitoring and assessment 2019, 191, 419.

20. Valko, M.; Rhodes, C.J.; Moncol, J.; Izakovic, M.; Mazur, M. Free radicals, metals and antioxidants in oxidative stress-induced cancer. Chemico-biological interactions 2006, 160, 1-40. 
21. Harrison, D.L.; Bates, P.J.J. The Mammals of Saudi Arabia 1991, 354-367.

22. Azizi, K.; Moemenbellah-Fard, M.D.; Fakoorziba, M.R.; Fekri, S. Gerbillus nanus (rodentia: Muridae): A new reservoir host of leishmania major. Annals of Tropical Medicine and Parasitology 2011, 105, 431437.

23. Preuss, H.G.; Jarrell, S.T.; Scheckenbach, R.; Lieberman, S.; Anderson, R.A. Comparative effects of chromium, vanadium and gymnema sylvestre on sugar-induced blood pressure elevations in shr. Journal of the American College of Nutrition 1998, 17, 116-123.

24. Grisham, M.B.; Johnson, G.G.; Lancaster, J.R., Jr. Quantitation of nitrate and nitrite in extracellular fluids. Methods Enzymol 1996, 268, 237-246.

25. Beutler, E.; Duron, O.; Kelly, B.M. Improved method for the determination of blood glutathione. The Journal of laboratory and clinical medicine 1963, 61, 882-888.

26. Marklund, S.; Marklund, G. Involvement of the superoxide anion radical in the autoxidation of pyrogallol and a convenient assay for superoxide dismutase. FEBS European Journal of Biochemistry 1974, 47, 469-474.

27. Cohen, G.; Dembiec, D.; Marcus, J. Measurement of catalase activity in tissue extracts. Analytical Biochemistry Analytical Biochemistry 1970, 34, 30-38.

28. Jaishankar, M.; Tseten, T.; Anbalagan, N.; Mathew, B.B.; Beeregowda, K.N. Toxicity, mechanism and health effects of some heavy metals. Interdiscip Toxicol 2014, 7, 60-72.

29. Organization, W.H. Lead poisoning and health. 2018.

30. Earth, P. The new top six toxic threats: A priority list for remediation, world's worst pollution problems report. 2015.

31. Mudipalli, A. Lead hepatotoxicity \& potential health effects. The Indian journal of medical research 2007, $126,518-527$.

32. El-Nekeety, A.A.; El-Kady, A.A.; Soliman, M.S.; Hassan, N.S.; Abdel-Wahhab, M.A. Protective effect of aquilegia vulgaris (1.) against lead acetate-induced oxidative stress in rats. Food and chemical toxicology : an international journal published for the British Industrial Biological Research Association 2009, $47,2209-2215$.

33. Jia, Q.; Ha, X.; Yang, Z.; Hui, L.; Yang, X. Oxidative stress: A possible mechanism for lead-induced apoptosis and nephrotoxicity. Toxicology mechanisms and methods 2012, 22, 705-710.

34. El-Tantawy, W.H. Antioxidant effects of spirulina supplement against lead acetate-induced hepatic injury in rats. Journal of traditional and complementary medicine 2016, 6, 327-331.

35. Jaishankar, M.; Tseten, T.; Anbalagan, N.; Mathew, B.B.; Beeregowda, K.N. Toxicity, mechanism and health effects of some heavy metals. Interdisciplinary toxicology 2014, 7, 60-72.

36. Flora, S.J.S.; Flora, G.; Saxena, G. Environmental occurrence, health effects and management of lead poisoning. In Lead chemistry, analytical aspects, environmental impacts and health effects, Cascas, S.B.; Sordo, J., Eds. Elsevier Publication: Amsterdam, The Netherlands, 2006; pp 158-228.

37. Adegbesan, B.O; Adenuga, G.A. Effect of lead exposure on liver lipid peroxidative and antioxidant defense systems of protein-undernourished rats. Biological trace element research 2007, 116, 219-225.

38. Li, Q.; Liu, H.; Alattar, M.; Jiang, S.; Han, J.; Ma, Y.; Jiang, C. The preferential accumulation of heavy metals in different tissues following frequent respiratory exposure to pm2.5 in rats. Scientific Reports 2015, 5, 16936.

39. Jarup, L.; Akesson, A. Current status of cadmium as an environmental health problem. Toxicology and applied pharmacology 2009, 238, 201-208. 
40. Thevenod, F.; Lee, W.K. Toxicology of cadmium and its damage to mammalian organs. Metal ions in life sciences 2013, 11, 415-490.

41. Satarug, S.; Garrett, S.H.; Sens, M.A.; Sens, D.A. Cadmium, environmental exposure, and health outcomes. Ciencia E saude coletiva 2011, 16, 2587-2602.

42. Casalino, E.; Sblano, C.; Landriscina, C. Enzyme activity alteration by cadmium administration to rats: The possibility of iron involvement in lipid peroxidation. Archives of biochemistry and biophysics 1997, 346, 171-179.

43. Jeyaprakash, K.; Chinnaswamy, P. Effect of spirulina and liv-52 on cadmium induced toxicity in albino rats. Indian journal of experimental biology 2005, 43, 773-781.

44. Vicente-Sanchez, C.; Egido, J.; Sanchez-Gonzalez, P.D.; Perez-Barriocanal, F.; Lopez-Novoa, J.M.; Morales, A.I. Effect of the flavonoid quercetin on cadmium-induced hepatotoxicity. Food and chemical toxicology : an international journal published for the British Industrial Biological Research Association 2008, $46,2279-2287$.

45. Shimada, H.; Yasutake, A.; Hirashima, T.; Takamure, Y.; Kitano, T.; Waalkes, M.P.; Imamura, Y. Strain difference of cadmium accumulation by liver slices of inbred wistar-imamichi and fischer 344 rats. Toxicology in vitro : an international journal published in association with BIBRA 2008, 22, 338-343.

46. Wang, J.; Hao, M.; Liu, C.; Liu, R. Cadmium induced apoptosis in mouse primary hepatocytes: The role of oxidative stress-mediated erk pathway activation and the involvement of histone h3 phosphorylation. RSC Adv. 2015, 5, 31798-31806.

47. Castagnetto, J.M.; Hennessy, S.W.; Roberts, V.A.; Getzoff, E.D.; Tainer, J.A.; Pique, M.E. Mdb: The metalloprotein database and browser at the scripps research institute. Nucleic acids research 2002, 30, 379-382.

48. Wang, Y.; Fang, J.; Leonard, S.S.; Rao, K.M. Cadmium inhibits the electron transfer chain and induces reactive oxygen species. Free radical biology \& medicine 2004, 36, 1434-1443.

49. Akomolafe, R.O.; Imafidon, C.E.; Olukiran, O.S.; Oladele, A.A.; Ajayi, A.O. Livolin forte ameliorates cadmium-induced kidney injury in wistar rats. Serbian Journal of Experimental and Clinical Research 2016, 17.

50. Bolognin, M.; Kirschvink, N.; Leemans, J.; De Buscher, V.; Snaps, F.; Gustin, P.; Peeters, D.; Clercx, C. Characterisation of the acute and reversible airway inflammation induced by cadmium chloride inhalation in healthy dogs and evaluation of the effects of salbutamol and prednisolone. Veterinary journal (London, England : 1997) 2009, 179, 443-450.

51. Oberdorster, G. Airborne cadmium and carcinogenesis of the respiratory tract. Scandinavian journal of work, environment $\mathcal{E}$ health 1986, 12, 523-537.

52. Takenaka, S.; Oldiges, H.; Konig, H.; Hochrainer, D.; Oberdorster, G. Carcinogenicity of cadmium chloride aerosols in w rats. Journal of the National Cancer Institute 1983, 70, 367-373.

53. Singh, N.; Kumar, D.; Sahu, A.P. Arsenic in the environment: Effects on human health and possible prevention. Journal of environmental biology 2007, 28, 359-365.

54. Hughes, M.F.; Beck, B.D.; Chen, Y.; Lewis, A.S.; Thomas, D.J. Arsenic exposure and toxicology: A historical perspective. Toxicological Sciences 2011, 123, 305-332.

55. Thangapandiyan, S.; Ramesh, M.; Miltonprabu, S.; Hema, T.; Jothi, G.B.; Nandhini, V. Sulforaphane potentially attenuates arsenic-induced nephrotoxicity via the pi3k/akt/nrf2 pathway in albino wistar rats. Environmental science and pollution research international 2019, 26, 12247-12263. 
56. Ling, S.; Shan, Q.; Liu, P.; Feng, T.; Zhang, X.; Xiang, P.; Chen, K.; Xie, H.; Song, P.; Zhou, L., et al. Metformin ameliorates arsenic trioxide hepatotoxicity via inhibiting mitochondrial complex i. Cell Death EAmp; Disease 2017, 8, e3159.

57. Mariappan, N.; Zafar, I.; Husain, M.; Vaid, M.; Surolia, R.; Kashyap, M.P.; Srivastava, R.; Ahmad, S.; Agarwal, A.; Athar, M., et al. Pulmonary manifestations of inhaled arsenic trioxide following an acute accidental exposure. In B31. Acute lung injury and ards: Translational and mechanistic studies, American Thoracic Society: 2018; pp A2974-A2974.

58. Patrick, L. Mercury toxicity and antioxidants: Part 1: Role of glutathione and alpha-lipoic acid in the treatment of mercury toxicity. Alternative medicine review : a journal of clinical therapeutic 2002, 7, 456471.

59. Boroushaki, M.T.; Mollazadeh, H.; Rajabian, A.; Dolati, K.; Hoseini, A.; Paseban, M.; Farzadnia, M. Protective effect of pomegranate seed oil against mercuric chloride-induced nephrotoxicity in rat. Renal Failure 2014, 36, 1581-1586.

60. Brandao, F.; Cappello, T.; Raimundo, J.; Santos, M.A.; Maisano, M.; Mauceri, A.; Pacheco, M.; Pereira, P. Unravelling the mechanisms of mercury hepatotoxicity in wild fish (liza aurata) through a triad approach: Bioaccumulation, metabolomic profiles and oxidative stress. Metallomics : integrated biometal science 2015, 7, 1352-1363.

61. Altamirano-Lozano, M.A.; Alvarez-Barrera, L.; Mateos-Nava, R.A.; Fortoul, T.I.; Rodriguez-Mercado, J.J. Potential for genotoxic and reprotoxic effects of vanadium compounds due to occupational and environmental exposures: An article based on a presentation at the 8th international symposium on vanadium chemistry, biological chemistry, and toxicology, washington dc, august 15-18, 2012. Journal of immunotoxicology 2014, 11, 19-27.

62. Castellini, C.; Mourvaki, E.; Sartini, B.; Cardinali, R.; Moretti, E.; Collodel, G.; Fortaner, S.; Sabbioni, E.; Renieri, T. In vitro toxic effects of metal compounds on kinetic traits and ultrastructure of rabbit spermatozoa. Reproductive toxicology (Elmsford, N.Y.) 2009, 27, 46-54.

63. Roshchin, A.V.; Ordzhonikidze, E.K.; Shalganova, I.V. Vanadium--toxicity, metabolism, carrier state. Journal of hygiene, epidemiology, microbiology, and immunology 1980, 24, 377-383.

64. Assem, F.L.; Levy, L.S. Inhalation toxicity of vanadium. In Vanadium: Biochemical and molecular biological approaches, Michibata, H., Ed. Springer Netherlands: Dordrecht, 2012; pp 209-224.

65. Stern, B.R. Essentiality and toxicity in copper health risk assessment: Overview, update and regulatory considerations. Journal of toxicology and environmental health. Part A 2010, 73, 114-127.

66. Kox, L.F.; Wosten, M.M.; Groisman, E.A. A small protein that mediates the activation of a twocomponent system by another two-component system. The EMBO journal 2000, 19, 1861-1872.

67. Albretsen, J. The toxicity of iron, an essential element. VETERINARY MEDICINE -BONNER SPRINGS THEN EDWARDSVILLE- 2006, 101, 82-90.

68. Ramm, G.A.; Ruddell, R.G. Hepatotoxicity of iron overload: Mechanisms of iron-induced hepatic fibrogenesis. Seminars in liver disease 2005, 25, 433-449.

69. Zager, R.A.; Johnson, A.C.M.; Hanson, S.Y. Parenteral iron nephrotoxicity: Potential mechanisms and consequences1. Kidney International 2004, 66, 144-156. 